\title{
Sensitivitas dan Spesifisitas Rasio Lingkar Pinggang Panggul (RLPP) dan Lingkar Perut (LP) sebagai Indikator Risiko Hipertensi pada Orang Dewasa
}

\author{
Ahdiyatul Fauza ${ }^{\text {a }}$, Ali Rosidi ${ }^{\mathrm{b}}$ \\ ${ }^{a}$ Magister Ilmu Gizi Universitas Diponegoro, Semarang \\ bProgram Studi Ilmu Gizi Universitas Muhammadiyah, Semarang \\ Alamat Korespondensi: Email: adivatulfauza@gmail.com 22alirhesa@yahoo.co.id
}

\begin{abstract}
Obesity is a risk factor for increased blood pressure and triglyceride levels, which then becomes a risk factor for cardiovascular disease. Measuring waist circumference ratio to know the high risk of DM II disease, cholesterol, hypertension, and heart. Measurement of abdominal circumference is done to determine whether there is abdominal or central obesity. This type of obesity is very influential on the incidence of disease complications. This research is a cross-sectional analytic research. Subjects of adults aged 30-60 years are from secondary data of metabolic syndrome study which has been examined for blood pressure and stomach circumference of 45 people in Laboratory of West Sumatera. The sensitivity and specificity tests were performed using Receiver Operator Characteristic Curve (ROC). Age of respondents in general in the range 50-60 years with a percentage of $64.4 \%$. Based on the ROC curve, RLPP has the ability to identify the standard hypertension indicator (AUC 0.783 ) is not good enough as an indicator to detect the risk of complications in hypertension and poor (poor AUC 0.648) as an indicator of hypertension risk. The ROC results show that RLPP is slightly better than LP but both are not reliable enough as indicators for hypertension.
\end{abstract}

Keywords: sensitivity, spesificity, RLPP, waist circumference, hypertension.

\begin{abstract}
Abstrak
Obesitas merupakan faktor risiko terjadinya peningkatan tekanan darah dan kadar trigliserida, yang selanjutnya menjadi faktor risiko penyakit kardiovaskular. Pengukuran rasio lingkar pinggang panggul untuk mengetahui resiko tinggi terkena penyakit DM II, kolesterol, hipertensi, dan jantung. Pengukuran lingkar perut dilakukan untuk mengetahui ada tidaknya obesitas abdominal atau sentral. Jenis obesitas ini sangat berpengaruh terhadap kejadian penyakit komplikasi. Penelitian ini merupakan penelitian observasional dengan pendekatan cross-sectional. Subjek orang dewasa usia 30-60 tahun berasal dari data sekunder penelitian sindrom metabolik yang memeriksakan tekanan darah dan lingkar perut berjumlah 45 orang di Balai Laboratorium Sumatera Barat. Uji sensitifitas dan spesifisitas dilakukan menggunakan Receiver Operator Characteristic Curve (ROC). Berdasarkan kurva ROC maka RLPP mempunyai kemampuan untuk mengidentifikasi indikator risiko hipertensi biasa/fair (AUC 0,783) belum cukup baik sebagai indikator untuk mendeteksi risiko komplikasi pada hipertensi sedangkan lingkar perut buruk/poor (AUC 0,648) belum baik sebagai indikator risiko hipertensi. Hasil ROC menunjukkan bahwa RLPP sedikit lebih baik dari LP tetapi keduanya tidak cukup andal sebagai indikator untuk hipertensi.
\end{abstract}

Kata kunci: sensitifitas, spesifisitas, RLPP, lingkar perut, hipertensi.

\section{PENDAHULUAN}

Obesitas merupakan masalah metabolisme yang terus meningkat di dunia. Obesitas merupakan penimbunan lemak berlebihan dalam jaringan di seluruh Fauza, A., dkk., RLPP dan LP sebagai indikator Hipertensi tubuh atau tempat tertentu seperti perut yang umumnya di sebut obesitas sentral atau obesitas abdominal (Lipoeto NI, 2007, p.23). Obesitas disebabkan oleh ketidakseimbangan energi yang positif (positive energy imbalance), yaitu jika 
asupan kalori yang berlebih tidak sebanding dengan pembakaran kalori melalui aktivitas fisik sehingga terjadi peningkatan berat badan (Reynolds dkk, 2008, p.128).

Obesitas terutama obesitas abdominal adalah faktor risiko untuk penyakit kardiovaskular (Seidell JC, 2008, p.203). Obesitas merupakan faktor risiko terjadinya peningkatan tekanan darah dan kadar trigliserida, yang selanjutnya menjadi faktor risiko penyakit kardiovaskular. Berdasarkan Hasil Penelitian Biomedis dan Farmasi Badan Penelitian Kesehatan Departemen Kesehatan RI oleh Rahajeng dan Tuminah (2009), kelompok obesitas meningkatkan risiko hipertensi sebesar 2,79 kali. Risiko hipertensi meningkat sebesar 1,40 kali pada orang dengan obesitas abdominal.

Peningkatan lemak tubuh (obesitas), terutama obesitas sentral berhubungan dengan peningkatan tekanan darah. Hal ini sesuai dengan penelitian yang menyatakan bahwa tekanan darah tinggi lebih banyak ditemukan pada individu dengan obesitas sentral dibandingkan dengan obesitas periferal (Simone G dkk, 2005, p.757). Wilsonn et al menemukan bahwa laki-laki dan perempuan yang mengalami obesitas sentral mempunyai tekanan darah sistol dan diastol, kolesterol total, kolesterol LDL, dan triasilgliserol rata-rata tinggi, serta kolesterol HDL rendah. (Sugianti, E 2009, dalam wilson).

Antropometri merupakan indikator yang telah lama dan sering digunakan dalam penentuan status gizi. Indeks antropometri dapat digunakan untuk mendeteksi obesitas sentral salah satunya adalah pengukuran Rasio Lingkar Pinggang-Panggul (RLPP). Indeks antropometri merupakan pengukuran yang mudah, cepat, murah, non-invasif, dan cukup akurat dalam memprediksi lemak viseral tubuh yang berkorelasi erat dengan sindrom metabolik (Supariasa, 2002).

Pengukuran rasio lingkar pinggang panggul untuk mengetahui resiko tinggi terkena penyakit DM II, kolesterol, hipertensi, dan jantung (Kristanti, 2010). Pengukuran lingkar perut dilakukan untuk mengetahui ada tidaknya obesitas abdominal atau sentral. Jenis obesitas ini sangat berpengaruh terhadap kejadian penyakit kardiovaskular dan diabetes mellitus (Sandjadja dkk, 2010).

Penelitian Park et al (2005), di Korea menunjukkan bahwa cut-off point LP yang berisiko terhadap kejadian penyakit akibat obesitas adalah $89,8 \mathrm{~cm}$ (Se $84,7 \%$ \& Sp 91,7\%) pada laki-laki dan $86,1 \mathrm{~cm}$ (Se 83,6\% \& Sp 62,9\%) pada perempuan. ${ }^{10}$ Cut-off point LP sebagai penentu obesitas sentral, menurut kriteria IDF (International Diabetes Federation), di Eropa $\geq 94 \mathrm{~cm}$ untuk laki-laki dan $\geq 80$ cm untuk perempuan. Asia Selatan dan China menggunakan cut-off point yang sama, yakni $\geq 90 \mathrm{~cm}$ untuk laki-laki dan $\geq$ $80 \mathrm{~cm}$ untuk perempuan (International Diabetes Federation, 2013).

Hasil-hasil penelitian di atas menunjukkan bahwa untuk mengukur status obesitas sentral dapat digunakan RLPP dan LP. RLPP dan LP lebih banyak digunakan pada penelitian klinis dan dalam praktiknya tidak semua orang mau diukur LP-nya dan digunakan untuk menilai obesitas abdominal serta merupakan indikator terbaik dalam menentukan risiko penyakit kardiovaskular.

\section{METODE}

Penelitian ini merupakan penelitian analitik cross-sectional. Pada penelitian ini data yang digunakan adalah data hasil penelitian di balai laboratorium provinsi sumatera barat. Sampel dalam penelitian ini adalah orang dewasa usia 30-60 tahun berasal dari data sekunder penelitian sindrom metabolik yang memeriksakan tekanan darah dan lingkar perut berjumlah 45 orang. Kriteria inklusi adalah orang dewasa usia 30-60 tahun, kriteria ekslusi adalah wanita hamil.

Penentuan sensitivitas (Se) dan spesifisitas (Sp) RLPP dan LP terhadap resiko hipertensi menggunakan analisis 
NERS: Jurnal Keperawatan,Volume 13, No. 1, Maret 2017, (Hal. 10-14)

kurva ROC. Pengolahan data menggunakan SPSS.

Tabel 3. Kategori RLPP dan Lingkar Perut

\section{HASIL}

Berdasarkan analisis data diperoleh hasil sebagai berikut :

Tabel 1. Karakteristik Umum Responden $(\mathrm{n}=45)$

\begin{tabular}{ll}
\hline Karakteristik & $\mathbf{n}(\%)$ \\
\hline Jenis Kelamin & \\
$\quad$ Laki-laki & $23(51,5)$ \\
$\quad$ Perempuan & $22(48,5)$ \\
Usia & \\
30-49 tahun & $16(35,6)$ \\
$\mathbf{5 0 - 6 0}$ tahun & $29(64,4)$ \\
\hline
\end{tabular}

Jenis kelamin responden hampir sama yaitu $23(51,5 \%)$ orang laki-laki dan $22(48,5 \%)$ orang perempuan. Terdapat 16 $(35,6 \%)$ orang responden yang berusia 30 49 yaitu termasuk dewasa matang tahun dan $29(64,4 \%)$ orang responden berusia 50-60 tahun yang sudah menuju lansia.

Tabel 2. Hasil Pengukuran Antropometri

\begin{tabular}{ll}
\hline Parameter & $\begin{array}{l}\text { Median (Terendah } \\
\text { dan Tertinggi) }\end{array}$ \\
\hline Lingkar Perut $(\mathbf{c m})$ & $91,00(77,0-127,0)$ \\
Lingkar Panggul $(\mathbf{c m})$ & $107,0(86,0-159,0)$ \\
RLPP & $0,91(0,70-0,96)$
\end{tabular}

Ket : RLPP (rasio lingkar pinggang dan panggul);

Berdasarkan pengukuran antropometri diperoleh median lingkar perut pada subjek tergolong lebar dan termasuk obesitas sentral., Kemudian untuk median lingkar panggul dapat diketahui bahwa pada subjek termasuk lingkar pinggul yang lebar sehingga diperoleh nilai median RLPP 0,91 .

\begin{tabular}{lllll}
\hline & & \multicolumn{2}{c}{ RLPP } & Total \\
\cline { 3 - 4 } LP & Beresiko & $\begin{array}{l}\text { Tidak } \\
\text { Beresiko }\end{array}$ & \\
& & 23 & 8 & 31 \\
& Tidak & $(95,8 \%)$ & $(38,1 \%)$ & \\
& $1(4,2 \%)$ & 13 & 14 \\
Beresiko & & $(61,9 \%)$ & \\
& & 24 & 21 & 45 \\
\hline
\end{tabular}

Ket :RLPP (rasio lingkar pinggang dan panggul); LP (lingkar perut).

Berdasarkan Tabel 3 didapatkan hasil bahwa ada 95,8\% responden yang terdeteksi berisiko hipertensi serta ada $61,9 \%$ responden yang tidak beresiko hipertensi dan tidak mengalami obesitas.

Tabel 4. Hasil Uji Diagnostik Indikator RLPP

\begin{tabular}{|c|c|c|}
\hline \multicolumn{3}{|c|}{ Parameter } \\
\hline Sensit & iitas & 0,95 \\
\hline Spesif & itas & 0,61 \\
\hline NPV & & 0,92 \\
\hline PPV & & 0,74 \\
\hline Ket & $\begin{array}{l}\text { :Se } \\
\text { (Spe } \\
\text { Prec } \\
\text { Prec }\end{array}$ & $\begin{array}{l}\text { (Sensitivitas); } \quad \mathrm{Sp} \\
\text { as); NPV (Negative } \\
\text { Value; PPV (Positive } \\
\text { Value }\end{array}$ \\
\hline
\end{tabular}

Berdasarkan Tabel 4 diperoleh sensitivitas dan spesifisitas untuk pengukuran RLPP terhadap resiko hipertensi termasuk kategori baik yaitu $0,95(95 \%)$ dan $0,74(74 \%)$

Tabel 5. Hasil Uji Diagnostik LP

\begin{tabular}{lc}
\hline Parameter & \\
\hline Sensitivitas & 0,87 \\
Spesifisitas & 0,71 \\
NPV & 0,83 \\
PPV & 0,77 \\
\hline Ket : Se (Sensitivitas); Sp (Spesifisitas); & NPV (Negative Predictive Value; \\
PPV (Positive Predictive Value \\
Berdasarkan tabel 5 untuk \\
pengukuran menggunakan LP diperoleh \\
sensitivitas dan spesifisitas yang juga \\
termasuk kategori baik yaitu 0,87 (87\%)
\end{tabular}


dan 0,71 (71\%). Diketahui bahwa untuk sensitivitas dan spesifisitas dari pengukuran RLPP dan LP sudah baik untuk menjadi indikator risiko kejadian hipertensi.

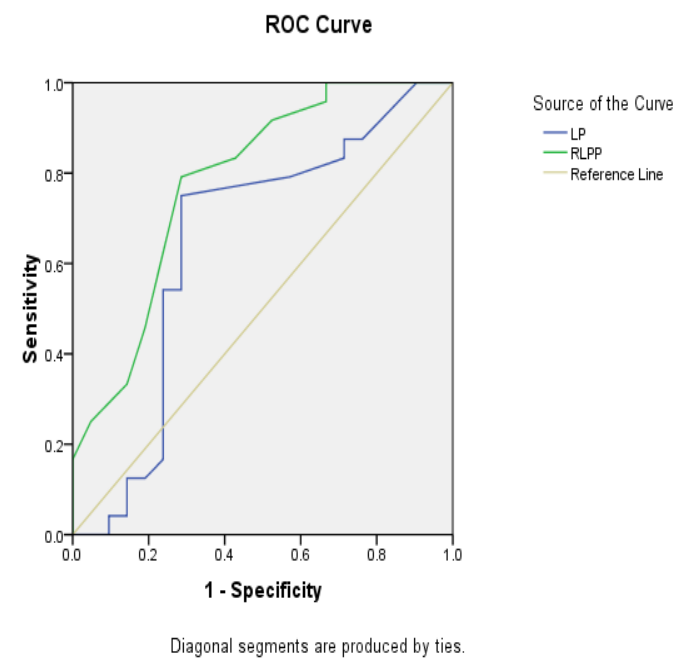

Gambar 1. Kurva ROC

Gambar $\quad 1$ menunjukkan perbandingan kurva ROC antara RLPP dan Lingkar Perut melihat indikator resiko hipertensi dan komplikasi penyakit lainnya. Tujuan dari analisis dengan ROC ini adalah untuk memaksimalkan nilai true positive (nilai yang menunjukkan bahwa subyek yang beresiko dengan benar) dengan nilai false positive yang bisa diterima). Gold standard yang digunakan pada pengukuran ini yaitu Tekanan darah. Nilai AUC pada RLPP ini menunjukkan hasil bahwa pengukuran RLPP biasa/fair $(0,783)$ untuk mendeteksi risiko komplikasi pada hipertensi. Nilai AUC pada LP ini menunjukkan hasil bahwa pengukuran LP buruk/poor $(0,648)$ untuk mendeteksi risiko hipertensi.

\section{PEMBAHASAN}

Hal-hal yang harus diperhatikan dalam suatu alat screening, antara lain adalah seberapa besar nilai sensitivitas dan spesifisitas serta seberapa besar nilai positif dan negatif "predictive value Seperti diketahui bahwa sensitivitas adalah probabilitas hasil tes menunjukkan hasil positif, jika pada gold standard hasilnya positif, sedangkan spesifisitas adalah probabilitas hasil tes menunjukkan hasil negatif, jika pada gold standard hasilnya negatif.

Selanjutnya untuk mengaplikasikan suatu tes, maka perlu biaya dan nilai. Oleh karena itu perlu dinilai seberapa besar nilai prediktif positif (NPP) dan nilai prediktif negatifnya (NPN). NPP diartikan sebagai probabilitas diperolehnya hasil gold standard positif, jika hasil tes positif atau persentase dari mereka dengan hasil tes positif yang benar-benar sakit, sedangkan NPN adalah probabilitas diperolehnya hasil gold standard negatif jika hasil tes negatif atau persentase dari mereka dengan hasil tes negatif dan tidak mempunyai penyakit. Setelah keempat ukuran tersebut diperoleh bagaimana memutuskan mana dari kedua alat tes tersebut yang akan digunakan maka yang harus dipertimbangkan adalah nilai PPV atau disebut juga NPP. Namun, secara ilmiah yang dilihat adalah validitas. Dalam kaitannya dengan penentuan hipertensi dan diabetes biasanya digunakan pemeriksaan tekanan darah, baik sistol maupun diastol, serta pemeriksaan kadar gula darah. Namun, ukuran-ukuran antropometri tertentu dapat digunakan sebagai indikator screening dengan cara yang cepat dan murah untuk memprediksi risiko hipertensi dan diabetes.

Untuk memprediksi risiko hipertensi bisanya dapat digunakan beberapa indikator antropometri, seperti RLPP ataupun LP, dan salah satu metode yang digunakan untuk menentukan cutt-off point adalah menggunakan uji ROC. Berdasarkan perhitungan Area Under Roc Curves (AUR) jika dibandingkan antara AUR RLPP dan LP belum cukup baik terhadap faktor risiko hipertensi, yaitu AUR RLPP lebih besar, AUR RLPP sebesar 0,783 dan AUR LP 0,648.

Analisis Sensitivitas (Se) dan Spesifisitas (Sp) untuk RLPP dan LP yaitu, sensitivitas untuk pengukuran RLPP terhadap resiko hipertensi yaitu 0,95 $(95 \%)$. Kemudian untuk spesifisitas 
pengukuran RLPP terhadap resiko hipertensi yaitu $0,74 \quad(74 \%)$. Untuk pengukuran menggunakan LP diperoleh sensitivitas 0,87 (87\%). Kemudian untuk spesifisitas pengukuran LP terhadap resiko hipertensi yaitu $0,71(71 \%)$.

Berdasarkan analisis ROC, RLPP mempunyai AUC 0,783 yang berarti belum cukup baik digunakan dalam mengklasifikasikan indikator risiko hipertensi. Kemudian LP mempunyai AUC 0,648 yang juga berarti belum cukup baik digunakan dalam mengklasifikasikan indikator risiko hipertensi. Ukuran lingkar pinggang orang Asia berdasarkan WHO dikatakan mengalami peningkatan risiko terkena penyakit tidak menular jika mempunyai lingkar pinggang/ perut $>80$ $\mathrm{cm}$, sedangkan lingkar pinggang/ perut $>88$ $\mathrm{cm}$ dikatakan secara substansial meningkatkan risiko penyakit degeneratif (WHO, 2008).

\section{KESIMPULAN DAN SARAN}

Pengukuran RLPP biasa/fair $(0,783$ belum cukup baik sebagai indikator untuk mendeteksi risiko komplikasi pada hipertensi. Pengukuran LP buruk/poor $(0,648)$ belum baik sebagai indikator risiko hipertensi. Hasil ROC menunjukkan bahwa RLPP sedikit lebih baik dari LP tetapi keduanya tidak cukup andal sebagai indikator untuk hipertensi.

Penggunaan RLPP dan LP tidak baik mendeteksi indikator risiko hipertensi sehingga tidak dianjurkan.

\section{DAFTAR PUSTAKA}

Lipoeto NI, Yerizel E, Edward Z, Widuri I. (2007). Hubungan nilai antropometri dengan kadar glukosa darah. (pp. 238). Medika

Reynolds KD, Klepp K, Yaroch AL. (2008). Strategi gizi masyarakat untuk intervensi di tingkat ekologis. Gizi kesehatan masyarakat. (pp. 128-44) Edisi ke-2. Jakarta: EGC.
Seidell JC, Visscher TLS. (2008). Aspek kesehatan masyarakat pada gizi lebih. Gizi kesehatan masyarakat. (pp. 20315) Edisi ke-2. Jakarta: EGC.

Rahajeng E, Tuminah S. (2009) Prevalensi hipertensi dan determinannya di Indonesia. vol. 59, no. 12, (pp. 5807). Majalah Kedokteran Indonesia.

Simone G, Devereux RB, Kizer JR, Chinali M, Bella JN, Oberman A, et al. (2005). Body composition and fat distribution influence systemic hemodynamics in the absence of obesity: the hyperGEN study. vol. 81, (pp. 757-61). American Journal of Clinical Nutrition.;

Sugianti, E. (2009). Faktor Risiko Obesitas Sentral Pada Orang Dewasa di Sulawesi Utara, Gorontalo dan DKI Jakarta. Skripsi. Bogor: Fakultas Ekologi Manusia Institut Bogor.

Supariasa. (2002). IGN. Penilaian Status Gizi. Jakarta: EGC.

Kristanti. (2010). Penyakit Akibat Kelebihan dan Kekurangan Vitamin, Mineral dan Elektrolit. Yogyakarta : Citra Pustaka.

Sandjadja dkk. (2010). Kamus Gizi Pelengkap Kesehatan Keluarga. Jakarta : Kompas.

Park HS, Yun YS, Park JY, Kim YS, Choi JM. (2003). Obesity, abdominal obesity, and clustering of cardiovascular risk factor in South Korea. . vol. 12, no. 4, (pp. 411-8). Asia Pacific JClin Nutr.

International Diabetes Federation. (2013). IDF Diabetes Atlas Sixth Edition. [Internet]. [cited 2017 Des 10]. Available from: www.idf.org/diabetesatlas

World Health Organization. (2008). WHO Expert Consultation. Waist Circumference and Waist-to-Hip Ratio [Dokumen di Internet]. Geneva: WHO; Available from: http://who.int. 